\title{
Corrigendum: Circulating tumour DNA profiling reveals heterogeneity of EGFR inhibitor resistance mechanisms in lung cancer patients
}

\author{
Jacob J. Chabon, Andrew D. Simmons, Alexander F. Lovejoy, Mohammad S. Esfahani, Aaron M. Newman, \\ Henry J. Haringsma, David M. Kurtz, Henning Stehr, Florian Scherer, Chris A. Karlovich, Thomas C. Harding, \\ Kathleen A. Durkin, Gregory A. Otterson, W. Thomas Purcell, D. Ross Camidge, Jonathan W. Goldman, \\ Lecia V. Sequist, Zofia Piotrowska, Heather A. Wakelee, Joel W. Neal, Ash A. Alizadeh \& Maximilian Diehn
}

Nature Communications 7:11815 doi: 10.1038/ncomms11815 (2016); Published 10 Jun 2016; Updated 14 Nov 2016

Previous work by Del Re et al. describing the emergence of KRAS mutations following treatment of non-small cell lung cancer patients with EGFR tyrosine kinase inhibitors was inadvertently omitted from the reference list of this Article and should have been cited as follows. The statement in the Results section 'While it is well established that KRAS activation is a mechanism of acquired resistance in colorectal cancer patients treated with EGFR-targeting monoclonal antibodies (mAbs) ${ }^{25,26,31,32}$, this is to our knowledge the

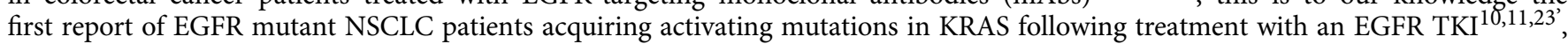
and the identical statement in the Discussion section, should both have read 'While it is well established that KRAS activation is a mechanism of acquired resistance in colorectal cancer patients treated with EGFR-targeting monoclonal antibodies (mAbs) ${ }^{25,26,31,32}$, here we show that EGFR mutant NSCLC patients can also acquire activating mutations in KRAS following treatment with a third generation EGFR TKI. The acquisition of KRAS mutations in EGFR mutant NSCLC patients following treatment with first line EGFR TKIs has recently been reported (Del Re et al.), although these mutations have not been detected in other similar first line cohorts ${ }^{10,11,23,24}$ '.

Del Re et al. contribution of KRAS mutations and c.2369C > T (p.T790M) EGFR to acquired resistance to EGFR-TKIs in EGFR mutant NSCLC: a study on circulating tumor DNA. Oncotarget doi: 10.18632/oncotarget.6957 (2016)

This work is licensed under a Creative Commons Attribution 4.0 International License. The images or other third party material in this article are included in the article's Creative Commons license, unless indicated otherwise in the credit line; if the material is not included under the Creative Commons license, users will need to obtain permission from the license holder to reproduce the material. To view a copy of this license, visit http://creativecommons.org/licenses/by/4.0/

(C) The Author(s) 2016 